\title{
Poly (threonine) Modified Carbon Composite Electrode as Sensor for Amoxicillin Determination
}

\author{
Nagaraja Sreeharsha ${ }^{1,2, *}$, Mallikarjun Telsang ${ }^{3}$, Girish Meravanige Basavarajappa ${ }^{4}$, \\ Swati Pund ${ }^{5}$, Ranjith Kumar Karnati ${ }^{6}$ \\ ${ }^{1}$ Department of Pharmaceutical Sciences, College of Clinical Pharmacy, King Faisal University, Al- \\ Ahsa 31982, Saudi Arabia; \\ ${ }^{2}$ Department of Pharmaceutics, Vidya Siri College of Pharmacy, Off Sarjapura Road, Bangalore \\ 560035, Karnataka, India \\ ${ }^{3}$ Department of Surgery, College of Medicine, King Faisal University, Al-Ahsa 31982, Saudi Arabia; \\ ${ }^{4}$ Department of Biomedical Sciences, College of Medicine, King Faisal University, Al-Ahsa 31982, \\ Saudi Arabia; \\ ${ }^{5}$ Nanomedicine Laboratory, Department of Biosciences and Bioengineering, Indian Institute of \\ Technology-Bombay, Mumbai 400076, India; \\ ${ }^{6}$ Department of Chemistry, College of Science, King Faisal University, Al-Ahsa 31982, Saudi Arabia \\ *E-mail: mvtelsang@kfu.edu.sa, sharsha@kfu.edu.sa
}

Received: 13 November 2021 / Accepted: 10 December 2021 / Published: 5 January 2022

The poly(threonine) carbon composite sensor was concentrated as a totally special sensor for the assurance Amoxicillin (AM). The behavior of AM at the electrode surface was researched utilizing electrochemical cyclic voltammetry (CV) and field emission scanning electron microscopy (FE-SEM). Electrochemical investigations uncovered that the projected sensor showed a significant benefit, involving high operative surface area, plentiful reactive spots and outstanding electro-catalytic action for the AM oxidation. In the ideal circumstances, the sensor showed a fine linear response towards the oxidation of $\mathrm{AM}$ in the concentration range from $0.10-16.0 \mu \mathrm{M}$. The assessed limit of detection and quantification were found to be $0.12 \mu \mathrm{M}$ and $0.45 \mu \mathrm{M}$ for AM, respectively. This sensor showed a good sensitivity, steadiness, selectivity, and reproducibility, proposed that the prepared sensor was a capable one for the concurrent assurance with dopamine (DA) and superb recuperation and without the impedances of existing together substances.

Keywords: Amoxicillin; Dopamine; polymerization; Electroanalysis.

\section{$\underline{\text { FULL TEXT }}$}

(C) 2022 The Authors. Published by ESG (www.electrochemsci.org). This article is an open access article distributed under the terms and conditions of the Creative Commons Attribution license (http://creativecommons.org/licenses/by/4.0/). 